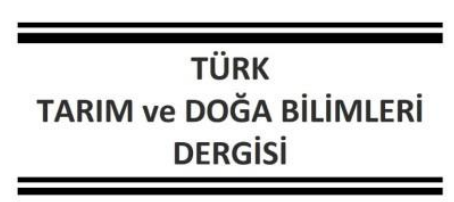

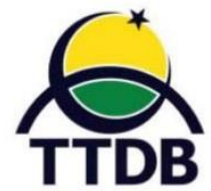

www.dergipark.gov.tr/turkjans

Araştırma Makalesi

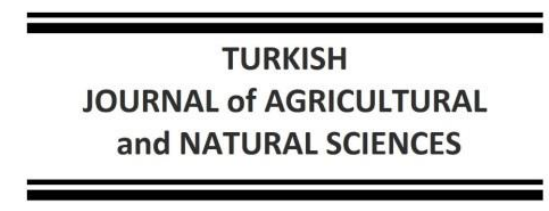

\title{
Arazi Toplulaştırma Projelerinin Arazi Parçalanma Değişimine Etkisi: Türkiye ve Polonya
} Örneği

\author{
Ela ERTUNÇ ${ }^{1 *}$, Jaroslaw JANUS ${ }^{2}$ \\ ${ }^{1}$ Konya Teknik Üniversitesi, Mühendislik ve Doğa Bilimleri Fakültesi, Harita Mühendisliği Bölümü, Konya-Türkiye \\ ${ }^{2}$ University of Agriculture in Krakow, Tarımsal Arazi Ölçmesi, Kadastro ve Fotogrametri Bölümü, Krakow- \\ Polonya \\ *Sorumlu Yazar: eertunc@ktun.edu.tr
}

Geliş Tarihi: 28.07.2020, Düzeltme Geliş Tarihi: 13.01.2021, Kabul Tarihi: 15.01.2021

Öz

Tarım arazilerinin parçalanması tüm dünyada yaygın bir problemdir ve bu problem tarım işletmeleri için arazi kullanımının, sürdürülebilir tarım ve rasyonel tarımsal kalkınmanın önündeki en büyük engellerden biridir. Arazi Toplulaştırması, arazi parçalanma etkilerini ortadan kaldırmak için parsellerin yeniden tahsisini içerir. Arazi Toplulaştırma projelerinden beklenen toplulaştırma sonrasında işletmelerin parsel sayılarını mümkün olduğunca en aza indirmektir. Böylece, Arazi Toplulaştırma projeleri ile arazi parçalılığı ve bununla birlikte işçilik, yol, sulama, bakım gibi girdiler azalmakta ve bu projelerden sağlanan verimi oldukça artırmaktadır. Bu nedenle arazi parçalılığının ölçülmesi, Arazi Toplulaştırma projelerinin planlanmasında ve sonuçlarının değerlendirilmesinde önemlidir. Arazi parçalılığı değerlendirilirken belirli bir işletmenin sahip olduğu parseller arasındaki mesafe faktörü dikkate alınmalıdır. Çünkü arazi parçalanması birçok parametreye dayanan mekânsal bir olgudur. Bundan dolayı, arazi parçalılığını belirlemede daha doğru bir yaklaşım için mekânsal yapının dikkate alınması gerekmektedir. Bu çalışmanın amacı Arazi Toplulaştırma öncesi ve sonrası parsellerin mekânsal dağılımını göz önünde bulundurarak Arazi Toplulaştırma projelerinin arazi parçalılığı üzerindeki etkisinin değerlendirilmesidir. Bunun içinde Türkiye ve Polonya'dan birer uygulama alanı üzerinde Arazi Toplulaştırmanın arazi parçalıı̆ı̆na etkisi incelenmiştir. Arazi parçalılığını ölçmek için; Average distance of a hectare indeksi, Grouping indeks, Structural indeks, Scattering indeks, Januszewski indeks ve Simmons's indeks'leri kullanılmıştır. Elde edilen sonuçlara göre arazi toplulaştırma projeleri sonucunda arazi parçalanmasının azaldığını göstermektedir. Ayrıca Arazi Toplulaştırma projelerinde arazi parçalılığın ölçülmesinde parseller arasındaki mesafeyi dikkate alan arazi parçalılık indesklerinin (Average distance of a hectare indeksi, Grouping indeks, Structural indeks, Scattering indeks) kullanımı önerilmektedir.

Anahtar kelimeler: Arazi toplulaştırma, arazi parçalanması, average distance of hectare indeks, grouping indeks, structural indeks

\section{Impact of Land Consolidation Projects on Land Fragmentation Change: The Case of Turkey and Poland}

\begin{abstract}
The fragmentation of agricultural land is a widespread problem all over the world and this problem is one of the biggest barriers to land use, sustainable agriculture and rational agricultural development for agricultural holdings. Land Consolidation includes the reallocation of plots to eliminate the effects of land fragmentation. What is expected from land consolidation projects is to minimize the number of parcels owned by holdings after consolidation as much as possible. Thus, with LC projects, land fragmentation and with it, inputs such as labor, roads, irrigation and maintenance are reduced and the effectiveness of these projects increases considerably. Therefore, measuring land fragmentation is significant in planning and evaluating the results of land consolidation projects. The distance factor between the parcels owned by a particular holding should be taken into account while evaluating the land fragmentation. Because, land fragmentation is a spatial phenomenon
\end{abstract}


based on many parameters. Therefore, the spatial structure needs to be taken into account for a more accurate approach in determining land fragmentation. The aim of this study is to evaluate the impact of land consolidation projects on land fragmentation by considering the spatial distribution of plots before and after land consolidation. Therefore, the effect of land consolidation on land fragmentation was examined on two application areas from Turkey and Poland. The Average distance of a hectare index, Grouping index, Structural index, Scattering index, Januszewski index and Simmons's index were used to measure land fragmentation. According to the results obtained, it shows that land fragmentation has decreased as a result of land consolidation projects. In addition, it is recommended to use land fragmentation indexes (Average distance of a hectare index, Grouping index, Structural index, Scattering index) that take into account the distance between parcels in the measurement of land fragmentation in Land Consolidation projects.

Key words: Land consolidation, land fragmentation, average distance of hectare index, grouping index, structural index

\section{Giriş}

Arazi parçalanması, bir işletmenin sahip olduğu toprağın birbirinden ayrı ve çok sayıda parçalara ayrılarak, arazi genişliğinin küçülmesi olarak tanımlanır (Ekinci ve Sayılı, 2010). Arazi parçalılığı, tarımsal üretimde düşük karlılığı etkileyen en önemli faktörlerden biridir (Gonzalez ve ark., 2007; Manjunatha ve ark., 2013; Deininger ve ark., 2014 ; Latruffe ve Piet, 2014). Çünkü tarım arazilerinin parçalı olmasının işçilik giderleri, makine verimi ve sulama projelerini olumsuz etkilemekte ve bu durumda tarım işletmelerinde arazi kullanımını, sürdürülebilir tarım ve rasyonel tarımsal kalkınmayı engellemektedir. Birçok ülke, tarım ekonomisi üzerinde doğrudan etkisi olan bu sorunla mücadele etmek için Arazi Toplulaştırma (AT) projelerini iyileştirici ve kırsal kalkınmayı da teşvik edici (Jürgenson, 2016) bir arazi yönetimi aracı olarak kullanmaktadır. Arazi Toplulaştırması, arazi parçalanma etkilerini ortadan kaldırmak için parsellerin yeniden tahsisini içerir. Arazi Toplulaştırma projelerine başlarken öncelikle çok parçalı arazilerin toplulaştırma projelerinin yapılması ile ilgili yasal bir zorunluluk yoktur. Ama, Arazi Toplulaştırma kanunlarında bu projelerin uygulama amaçlarından biri parçalı arazilerin birleştirilmesidir.

Arazi Toplulaştırma projeleri, başlangıçta esas olarak Avrupa'da (Hartvigsen, 2014), ancak günümüzde dünyanın en iç bölgelerinde, özellikle de arazi parçalanmasının kaçınılmaz olduğu bölgeler de uygulanmaktadır. Polonya ve Türkiye'de bu ülkelerden sadece ikisidir. Polonya'nın 1918 'de bağımsızlığını geri kazanmasının ardından ilk Arazi Toplulaştırma yasası Temmuz 1923 'te kabul edilmiştir (Markuszewska, 2013). Yasanın temel amacı arazi parçalanmasını azaltmaktır. Şu an 26 Mart 1982 tarihli “Arazi Toplulaştırması ve Değişimi Hakkında"ki kanuna göre Arazi Toplulaştırma projeleri yapılmaktadır (11 sayılı Kanunların Bülteni, madde. 80, sonraki değişikliklerle). Yasanın birinci maddesinde, Arazi Toplulaştırmasının amacı, tarımsal işletmelerin, ormanların ve orman arazilerinin mekânsal yapısının iyileştirilmesi, arazinin yeniden yapılanması ve parsellerin drenaj sistemine, yollara ve topografyaya uyarlanması yoluyla tarım ve ormancılıkta daha elverişli çalışma koşulları yaratmak olarak tanımlanmıştır. Polonya'daki arazi toplulaştırması, Hollanda ve Almanya'nın geleneksel yaklaşımına benzer zorunlu bir yaklaşım izlemektedir. Projeler, arazi sahiplerinin resmi talepleri üzerine başlatılır. Proje alanının \%50 'sinden fazlasını temsil eden arazi sahiplerinin \%50 'sinden fazlası projenin uygulanması için onay verirse, Powiat Başkanına, Starosta bir arazi toplulaştırma projesi için bir başvuru yapılır. Tarım ve Kırsal Kalkınma Bakanlığı (Arazi Yönetimi Bölümü) ulusal arazi toplulaştırma programının yürütülmesinden sorumludur. 1998 yılına kadar Bakanlık, arazi toplulaştırma projelerinin uygulanmasından da doğrudan sorumluydu fakat şu an Powiat başkanı projelerin uygulanmasından ve onaylanmasından sorumludur (ülkede toplam 314 Powiat vardır). Türkiye'de Arazi Toplulaştırma çalışmaları; 1984 tarih 3083 sayılı "Sulama Alanlarında Arazi Düzenlemesine Dair Tarım Reformu Kanunu'na göre TRGM ve 2005 tarih ve 5403 sayılı "Toprak Koruma ve Arazi Kullanım Kanunu'na göre çıkarılan 2009 tarihli Arazi Toplulaştırma Tüzüğü (ATT)'ne göre kamu kişilikleri tarafından yapılmaktadır. 28 Nisan 2018 tarih, 7139 sayılı “Devlet Su İşleri Genel Müdürlüğü’nün Teşkilat ve Görevleri Hakkında Kanun'daki değişiklik ve 7 Şubat 2019 tarihli, “Arazi Toplulaştırması ve Tarla İçi Geliştirme Hizmetleri Uygulama Yönetmeliği'ne göre Arazi Toplulaştırma yetkisi Devlet Su İşleri (DSi) Denel Müdürlüğü'ne verilmiştir. Diğer kamu kişiliklerinin arazi toplulaştırma yapabilmesi DSi'nin iznine bağlıdır.

Polonya'da ortalama işletme büyüklüğü 8 hektar (ha), ortalama parsel büyüklüğü 1.23 ha ve ülkede yaklaşık 1425 milyon tarımsal işletme vardır. Türkiye'de ortalama işletme büyüklüğü 5.9 ha, ortalama parsel büyüklüğü 1.09 ha ve yaklaşık 3 milyon tarımsal işletme mevcuttur. Her iki ülkede de 
tamamlanan Arazi Toplulaştırma çalışmalarının yıllara göre dağılımı Şekil 1 ve Şekil 2'de verilmiştir.
Şekil 1'de Türkiye'de 2023 yılına kadar tamamlanması hedeflenen sayı verilmiştir.

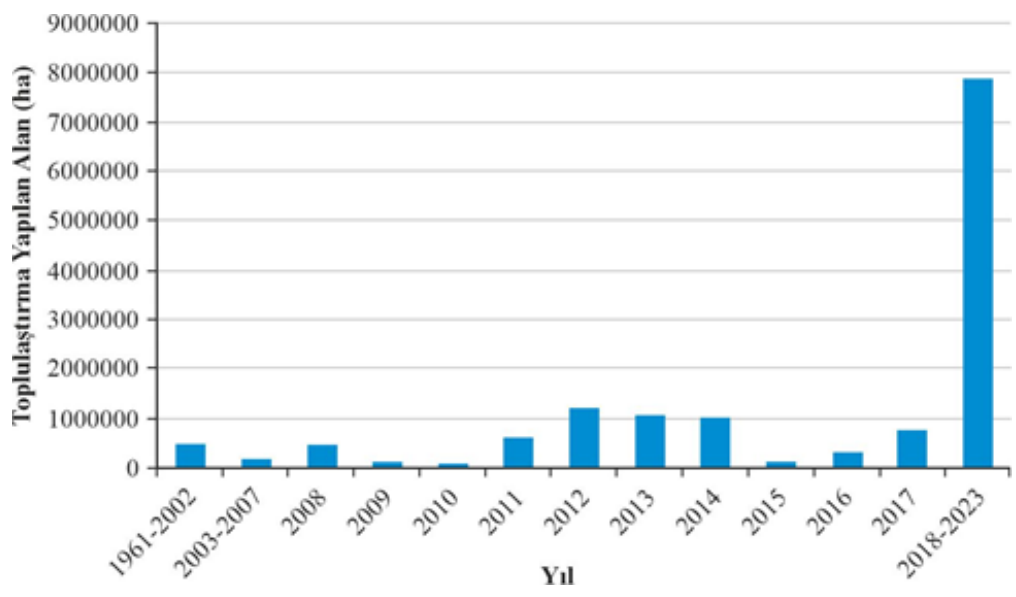

Şekil 1. Türkiye'de yapılan Arazi Toplulaştırma projelerinin yıllara göre dağılımı (Ayten, 2019)

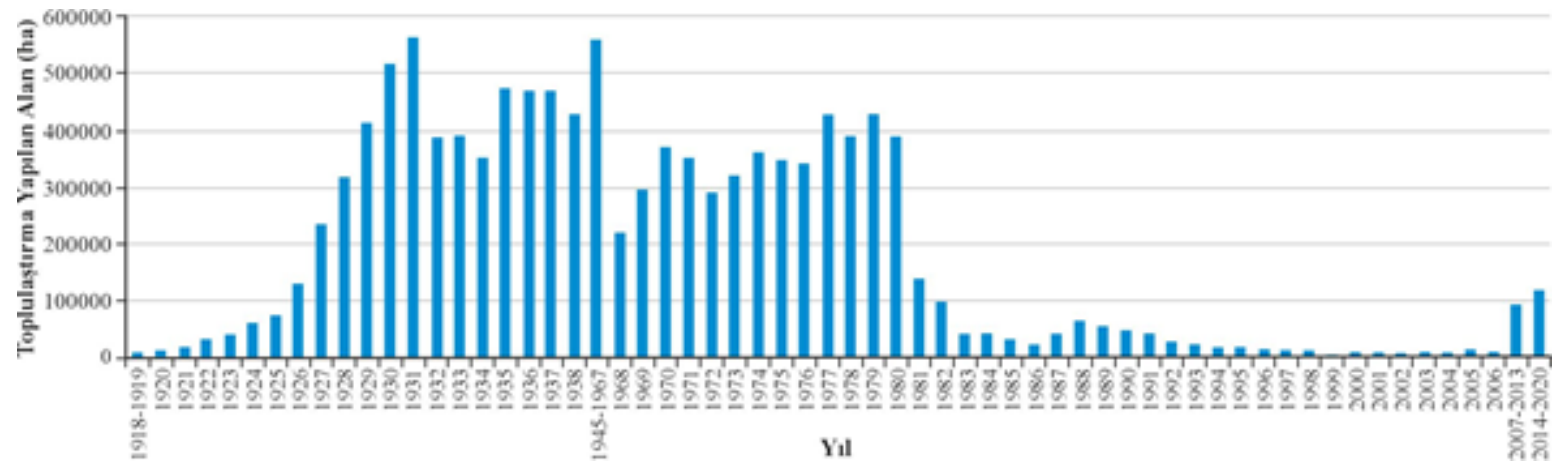

Şekil 2. Polonya'da yapılan Arazi Toplulaştırma çalışmalarının yıllara göre dağılımı (Janus ve Markuszewska, 2017)

Arazi parçalılığını ölçmek için, bugüne kadar çoğunlukla sadece bir işletmenin alanını ve parsel sayısını dikkate alan basitleştirilmiş parçalanma indeksleri geliştirilmiş ve çalışmalar daha çok bu alanda yaygınlaşmıştır. Bu tür indekslerden en yaygın kullanıma sahip olanlar Januszewski indeksi (Januszewski, 1968) ve Simmons's indeksi (Simmons, 1964) 'dir. Demetriou ve ark. (2013) Kıbrıs'ta yapılan bir arazi toplulaştırma projesinde, Januszewski ve Simmons's indekslerini kullanarak arazi parçalanmasını ölçmüşlerdir. Vijulie ve ark. (2012) ve Hristov (2009) tarım arazilerinde arazi parçalanmasının tarımsal üretimi nasıl etkilediğini belirlemek amacıyla yine Januszewski ve Simpson indekslerini kullanmışlardır. Looga ve ark. (2018)'nın çalışmasında Januszewski indeksi kullanılarak arazi parçalanmasının tarımsal verimlilik üzerindeki etkisi incelenmiştir. Akkaya Aslan (2018) 'ın çalışmasında Simmons's ve Januszewski indeksleri kullanılmış, Denizli'de yapılan bir projede toplulaştırma öncesi ve sonrası parçalılık değerlendirmesi yapılmıştır. Popov (2017) 'un yaptığı çalışmada Ukrayna'da yapılan arazi toplulaştırma projesinde, arazi parçalılığını ölçmek için Simmons's ve Januszewski indeksleri kullanılmıştır. Katona ve ark. (2017) 'nın çalışmasında arazi parçalılık değişimini belirlemek için Simmons's ve Januszewski indeskleri kullanılmıştır. Ciaiain ve ark (2018) 'nın çalışmalarında Arnavutluk'taki arazi parçalanması ve üretim çeşitliğinin belirlenmesinde yine Simpson indeksi kullanılmıştır. Ertunç (2020) çalışmasında arazi toplulaştırma projelerinin etkilerini değerlendirmek için Simmon's ve Januszewski indekslerini kullanmıştır. Bu indeksler, işletme merkezinin yeri ve parsellerin fiili düzenlenmesi veya şekilleri hakkında herhangi bir veri olmasa da hesaplanabilir. Bundan dolayı, bu tür endekslere dayanarak elde edilen herhangi bir sonuç hatalı olabilir, fakat arazi toplulaştırma projelerinin etkilerini değerlendirmek veya arazi parçalanmasının ekonomik değerlendirmesi için bu indeksler kullanılırlar.

Aslında, arazi parçalanması birçok parametreye dayanan mekânsal bir olgudur. Bundan dolayı, arazi parçalılığını belirlemede daha doğru bir yaklaşım için mekânsal yapının dikkate 
alınması gerekmektedir. Bu şekilde, belirli bir işletmenin veya bütün bir köydeki arazi toplulaştırmasının doğruluğunu değerlendirirken mesafe faktörü dikkate alınmalıdır. Arazi parçalılığında mesafeyi açıklayan en yaygın kullanılan parçalanma indeksleri: Average distance of a hectare indeks'i, Grouping indeks, Structural indeks, Scattering indeks'tir (Janus ve Markuszewska, 2017). Latruffe ve Piet (2014) çalışmalarında arazi parçalanmasının işletme performansı üzerindeki etkilerini bu indeksleri kullanarak incelemişlerdir. Janus ve Markuszewska (2017) çalışmalarında Polonya'da 2007-2013 yılları arasında gerçekleştirilen arazi toplulaştırma projelerinin sonuçlarını bu indeksleri kullanarak değerlendirmişlerdir.

Bu çalışmada da arazi toplulaştırma projelerinin arazi parçalanma değişimine etkisi iki farklı ülke de yapılan arazi toplulaştırma proje verisi kullanılarak incelenmiştir. Arazi parçalıı̆ı̆ını ölçmek için Average distance of a hectare indeksi (avdha), Grouping indeks (grpg), Structural indeks (stru), Scattering indeks (scatt), Januszewski indeksi (janus) ve Simmon's indeks (simm)'leri kullanılmıştır. Çalışmanın sonucunda Arazi Toplulaştırma projelerinin arazi parçalılığını azaltmadaki etkisi incelenmiştir.

\section{Materyal ve Metot}

Bu çalışmada Türkiye ve Polonya'dan birer Arazi Toplulaştırma projesi verisi materyal olarak alınmıştır (Şekil 3). Proje alanı, parsel sayısı, işletme sayısı, ortalama işletme büyüklüğü ve ortalama parsel büyüklüğü bilgileri Çizelge 1 'de verilmiştir.

Çalışmada kullanılan arazi parçalılık indeksleri aşağıdaki gibi tanımlanır:

Parselin büyüklüğüne ilişkin arazi parçalılığı tanımlayıcıları; Simmons's indeksi ve Januszewski indeksi'dir. $\mathrm{Bu}$ indeksler bireysel arsa büyüklüklerinin dağılımı hakkında bilgi içermektedir ve;

$\operatorname{avpls}_{i}=\frac{A_{i}}{K_{i}}$

Ortalama parsel büyüklüğü:

- Simmons's indeks:

$$
\operatorname{simm}_{i}=1-\frac{\sum_{k=1}^{K_{i}} a_{k}^{2}}{A_{i}^{2}}
$$

- Januszewski indeks:

janus $_{i}=\frac{\sqrt{A_{i}}}{\sum_{k=1}^{K_{i}} \sqrt{a_{k}}}$

formülleri ile hesaplanır.

Parselin mesafesini dikkate alan arazi parçalılık tanımlayıcıları;

- Average distance of a hectare:

$\operatorname{avdha}_{i}=\frac{1}{A_{i}} \sum_{k=1}^{K_{i}} a_{k} \sqrt{\left(x_{k-\bar{x}_{i}}\right)^{2}+\left(y_{k-\bar{y}_{i}}\right)^{2}}$

- Grouping indeks:

$\operatorname{grpg}_{i}=\frac{\arg \max _{k=1}^{K_{i}}\left(\sqrt{\left(x_{k-\bar{x}_{i}}\right)^{2}+\left(y_{k-\bar{y}_{i}}\right)^{2}}\right.}{\sqrt{A_{i} / \pi}}$

- Structural indeks:

strui $_{i=} \frac{\text { grpg }_{i}}{\text { avpls }_{i}}=\frac{\arg \max _{k=1}^{K_{i}}\left(\sqrt{\left(x_{k-\bar{x}_{i}}\right)^{2}+\left(y_{k-\bar{y}_{i}}\right)^{2}}\right.}{A_{i} \sqrt{A_{i} / \pi}}$

- Scattering indeks (Normalize edilmiş ortalama en yakın komşu mesafesi indeksi):

scatt $_{i}=\frac{\sum_{k=1}^{K_{i}} \arg \min _{k=1}^{K_{i}}\left(\sqrt{\left(x_{k-\bar{x}_{i}}\right)^{2}+\left(y_{k-\bar{y}_{i}}\right)^{2}}\right.}{K_{i} \sqrt{A_{i} / \pi}}$

formülleri ile hesaplanır.

Burada:

$A_{i}:$ "i" indeksi ile işletmenin toplam alanı,

$K_{i}$ : "i" indeksi ile işletmenin sahip olduğu parsel sayısı,

$a_{k}$ : " $\mathrm{k}$ " indeksi ile işletmenin farklı bir parselinin alanı, burada $\mathrm{k}=1$... Ki,

$\overline{x_{l}} \overline{y_{l}}:$ : $\mathrm{i}$ " indeksi ile parselin ağırlık merkezinin koordinatları,

$x_{k}, y_{k}$ : " $\mathrm{k}$ " indeksi ile parselin merkezinin koordinatlarıdır.

Aşağıdaki formül, işletmenin ağırlık merkezinin koordinatlarını elde etmek için kullanılır: $\left(\overline{x_{\imath}} \bar{y}_{\imath}\right)=\left(\frac{1}{A_{i}} \sum_{k=1}^{K_{i}} a_{k x_{k}}, \frac{1}{A_{i}} \sum_{k=1}^{K_{i}} a_{k y_{k}}\right)$

Köy merkezinin koordinatları aşağıdaki formülden hesaplanır:

$c_{v^{l}}=\left(x_{c v^{l}} y_{c v^{l}}\right)=\left(\frac{1}{A_{v}} \sum_{k=1}^{n} a_{k} x_{k} \frac{1}{A_{v}} \sum_{k=1}^{n} a_{k} y_{k}\right)$
Burada,

$a_{k}:$ " $\mathrm{k}$ " indeksi ile işletmenin alanıdır.

Çizelge 1. Proje alanlarına ait bilgiler

\begin{tabular}{|c|c|c|c|c|}
\hline & \multicolumn{2}{|c|}{ Abditolu } & \multicolumn{2}{|c|}{ Wysoka } \\
\hline & AT öncesi & AT sonrası & AT öncesi & AT sonrası \\
\hline Proje Alanı (ha) & 2532.40 & 2491.19 & 736 & 730 \\
\hline Parsel Sayısı & 946 & 459 & 3542 & 2075 \\
\hline İşletme Sayısı & 393 & 393 & 491 & 491 \\
\hline Ortalama İşletme Büyüklüğü (ha) & 6.18 & 6.32 & 1.5 & 1.5 \\
\hline Ortalama Parsel Büyüklüğü (ha) & 2.57 & 5.42 & 0.21 & 0.35 \\
\hline
\end{tabular}




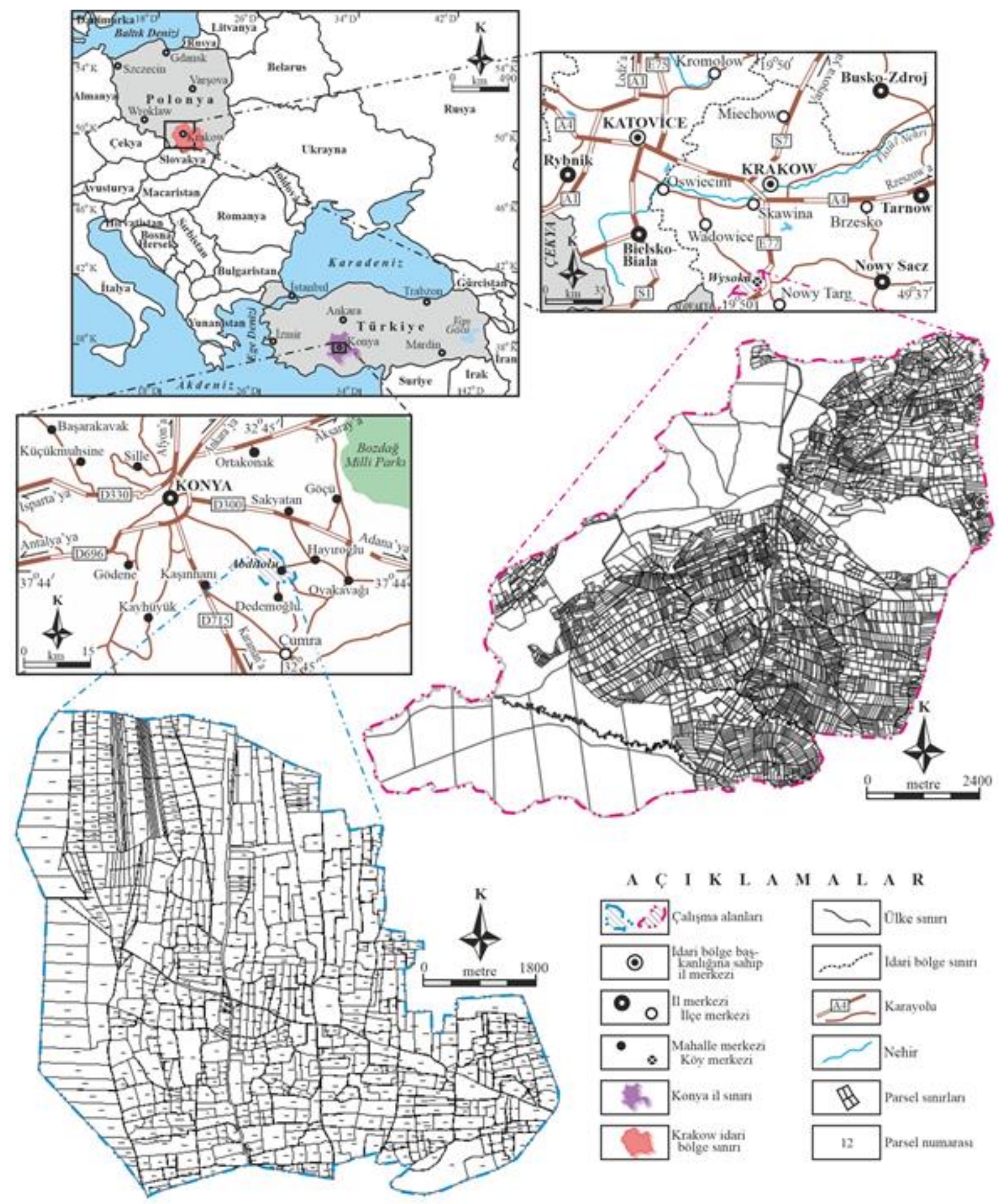

Şekil 3. Arazi Toplulaştırma proje alanları

\section{Bulgular ve Tartışma Abditolu}

Şekil 4 'de AT öncesi ve sonrası Simmons's indeks ve Januszewski indeks değerlerinin işletme sayılarına göre dağılımı verilmiştir. AT öncesi Simmons's ve Januszewski indeksi 1.00 olan işletme sayısı 240 iken AT sonrası bu sayı 348 'e çıkmıştır. Abditolu proje alanı için bu indeks değerleri \%27.5 artmıştır. AT öncesinde Simmons's indeksi değeri 0.40 'dan küçük olan işletmeler \%20.4 iken, AT sonrasında bu oranın \% 2'ye düştüğü görülmektedir.
Bu indeks değerinin 1 'den uzaklaşması işletmelerin parçalı olduğu anlamına gelir. Januszewski indeks değerinin 1 olması işletmenin bir tek parseli olduğunu gösterirken, 1 'den küçük değerler parsel sayısının arttığını göstermektedir. Januszewski indeksi'ne göre de indeks değeri 0.40 'dan düşük olan işletme oranı AT öncesi \%5 iken, AT sonrası Januszewski indeks değeri 0.40 'ın altında olan işletme kalmamıştır. Yine Simmons's indeks değeri 0.60 'tan büyük olan işletmelerin oranı AT öncesi \%63.6 iken, AT sonrası \%91.9 'a yükselmiştir. 
Januszewski indeks değeri 0.60 'tan büyük olan işletmelerin oranı AT öncesi \%77 iken, AT sonrası \%97.7'ye yükselmiştir.
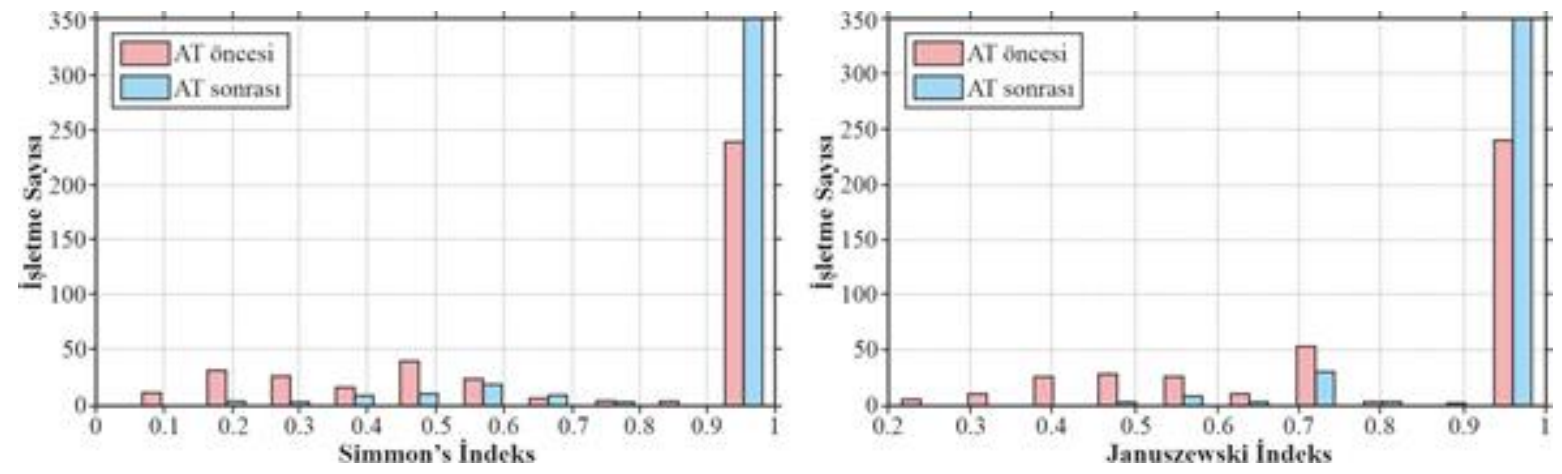

Şekil 4. Abditolu için AT öncesi ve sonrası Simmons's ve Januszewski İndeks değerleri

Şekil 5 'de AT öncesi ve sonrası Average Distance of Hectare Indeks ve Grouping Indeks değerlerinin işletme sayılarına göre dağılımı verilmiştir. $\mathrm{Bu}$ indekslerin değerlerinin düşük olması, daha az arazi parçalılığının olduğunu gösterir (Janus ve Markuszewska, 2017). Average Distance

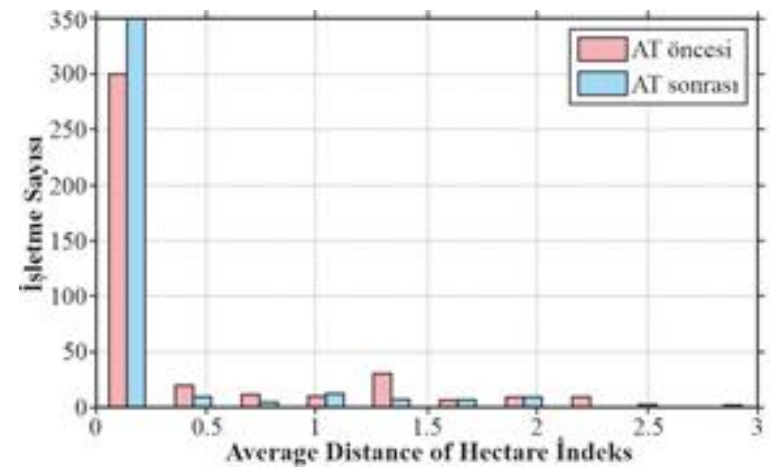

of Hectare indeksine göre indeks değeri 1'den düşük olan işletme oranı AT öncesi \%90.24 iken, AT sonrası \%92.37 olmuştur. Grouping indeksine göre indeks değeri 10 'dan düşük olan işletme oranı AT öncesi \%87.53 iken, AT sonrası \%96.18 olmuştur.

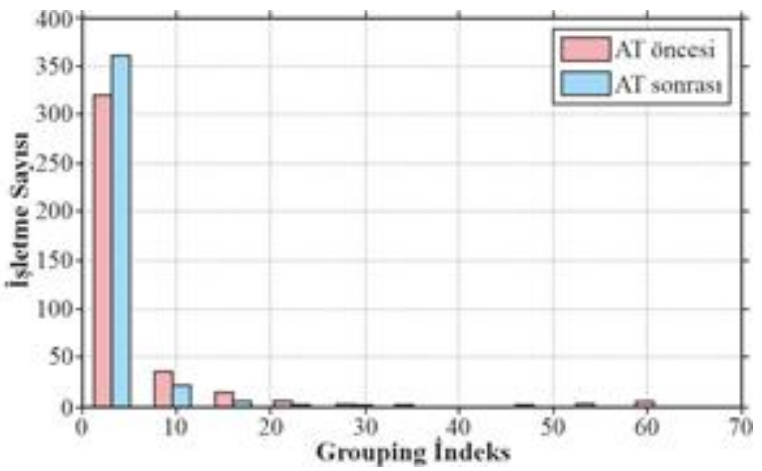

Şekil 5. Abditolu için AT öncesi ve sonrası Average Distance of Hectare Indeks ve Grouping Indeks değerleri

Şekil 6 'da AT öncesi ve sonrası Structural Indeks ve Scattering Indeks değerlerinin işletme sayılarına göre dağılımı verilmiştir. Bu indekslerin de değerlerinin düşük olması, daha az arazi parçalılığının olduğunu göstermektedir. AT

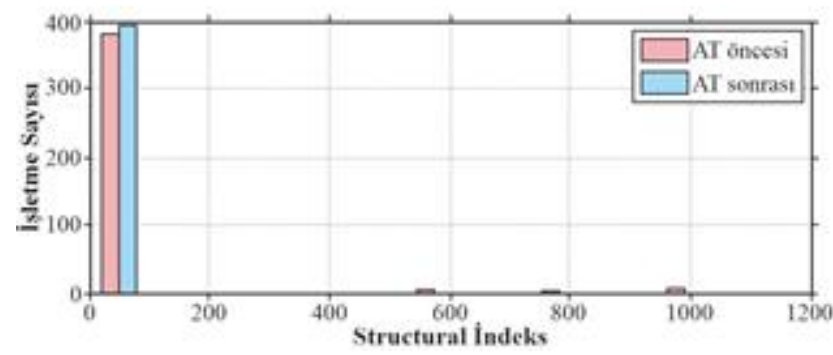

öncesinde Structural indeks değeri 0-10 arasında \%90.08 iken, AT sonrasında \%99.5 'e çıkmıştır. AT öncesinde Scattering indeks değeri 0-5 arasında olan işletme sayısı \%78.6 iken, AT sonrasında \%89.8 olmuştur.

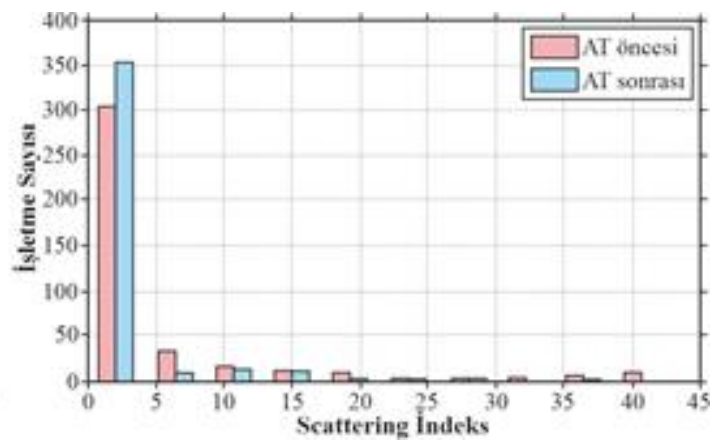

Şekil 6. Abditolu için AT öncesi ve sonrası Structural Indeks ve Scattering İndeks değerleri 


\section{Wysoka}

Şekil 7'de AT öncesi ve sonrası Simmons's ve Januszewski Indeks değerlerinin işletme sayılarına göre dağılımı verilmiştir. AT öncesi Simmons's ve Januszewski indeksi 1.00 olan işletme sayısı 117 iken AT sonrası bu sayı 159 'a çıkmıştır. Wysoka proje alanı için bu indeks değerleri \%8.6 artmıştır. Simmons's indeks değeri 0.40 'tan daha düşük işletmelerin oranı AT öncesinde \%53.2 iken, AT

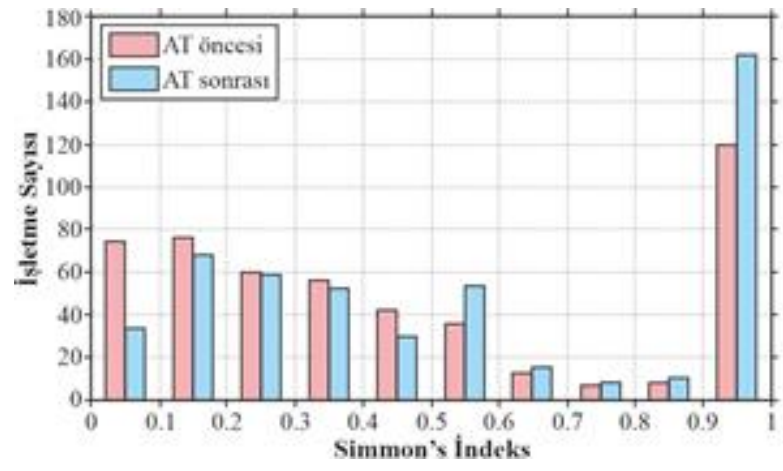

sonrasında bu oranın \%40.5 'e düştüğü görülmektedir. Januszewski indeksine göre de indeks değeri 0.40 'dan düşük olan işletme oranı AT öncesi \%30.7, AT sonrası \%18.7 'ye düşmüştür. Simmons's indeks değeri 0.60 'tan büyük olan işletmelerin oranı AT öncesi \%30,6 'dan, AT sonrası $\% 39.7$ 'ye yükselmiştir. Januszewski indeks değeri 0.60 'dan büyük olan işletmelerin oranı AT öncesi $\% 45.2$ iken, AT sonrası \%56.2 'ye yükselmiştir.

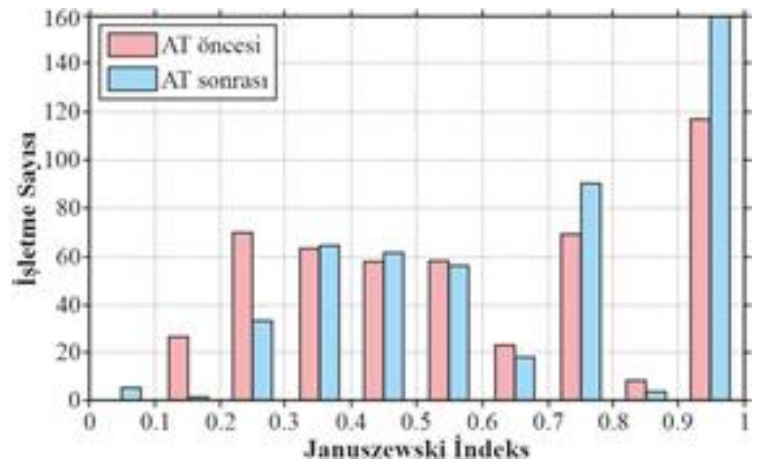

Şekil 7. Wysoka için AT öncesi ve sonrası Simmons's ve Januszewski İndeks değerleri

Şekil 8 'de AT öncesi ve sonrası Average Distance of Hectare Indeks ve Goruping Indeks değerlerinin işletme sayılarına göre dağılımı verilmiştir. Average Distance of Hectare indeksine göre indeks değeri 1 'den düşük olan işletme oranı

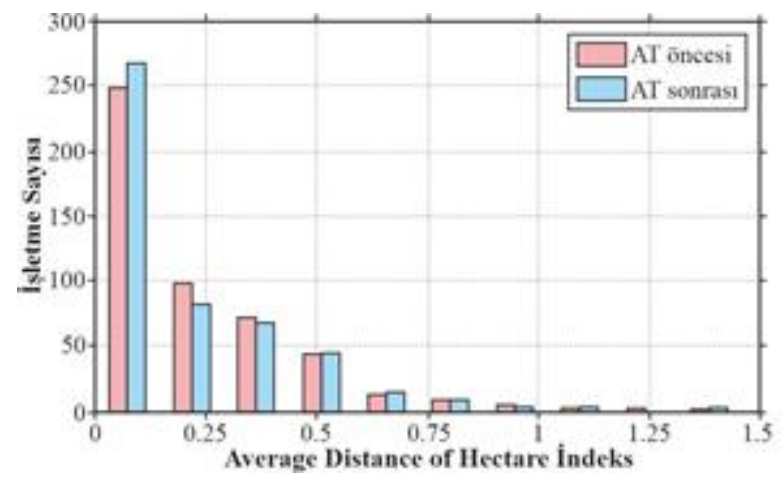

AT öncesi ve sonrasında 486 'dır. AT öncesi ve sonrası durumda bu indeks değerine göre bir değişiklik olmamıştır. Grouping indeksine göre indeks değeri 10 'dan düşük olan işletme oranı AT öncesi \%77.6 iken, AT sonrası \%81.26 olmuştur.

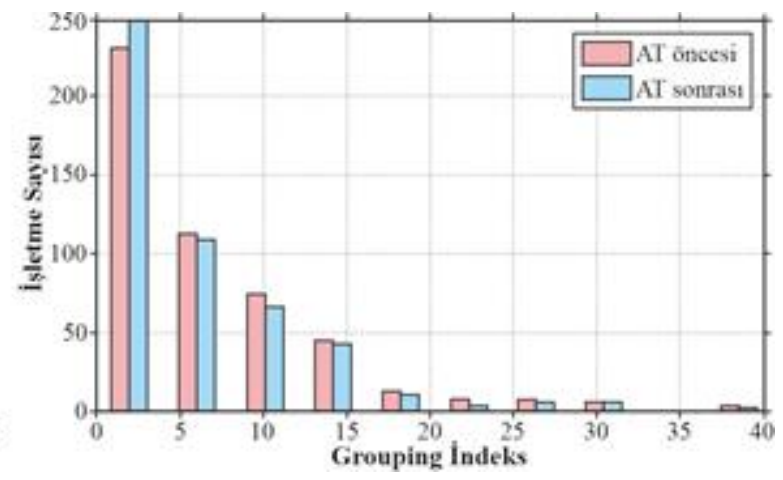

Şekil 8. Wysoka için AT öncesi ve sonrası Average Distance of Hectare Indeks ve Grouping Indeks değerleri

Şekil 9 'da AT öncesi ve sonrası Structural Indeks ve Scattering Indeks değerlerinin işletme sayılarına göre dağılımı verilmiştir. AT öncesinde Structural indeks değeri 0-10 arasında \%38.40 iken, AT sonrasında \%48.2 'ye çıkmıştır. AT öncesinde Scattering indeks değeri 0-5 arasında olan işletme sayısı \%58.04 iken, AT sonrasında \%62.9 olmuştur.

\section{Sonuç ve Öneriler}

Arazi parçalılık göstergeleri bilgisi, işletmelerin ve tüm tarım bölgelerinin işleyişinin ekonomik bir değerlendirmesinin yapılmasına, parsellerin yapısının değiştirilmesi ile ilgili çalışmaların yapılması konusunda tavsiyede bulunulmasına izin vermektedir. Bu nedenle arazi parçalılığının ölçülmesi, Arazi Toplulaştırma projelerinin planlanmasında ve sonuçlarının değerlendirilmesinde de önemlidir.

Arazi parçalılığını sadece alansal büyüklüğe ve parsel sayısına göre değerlendiren Januszewski ve Simmons's indekleri ve mesafeye dayalı olarak arazi parçalılığını ölçen Average distance of a hectare indeksi, Grouping indeks, Structural indeks, Scattering indeks değerleri AT sonrasında her iki ülkede de arazi parçalılığının azaldığını göstermektedir. AT sonrasında indeks değerlerinde ki değişiklikler her proje alanında farklılık göstermektedir. Çünkü her proje kendine has özellikler barındırmaktadır ve her projeden aynı verimi almak mümkün değildir. Parsellerin 
mesafesini dikkate alan arazi parçalılık indeksleri (Averge distance of a hectare, Grouping indeks, Structural indeks, Scattering indeks), sadece bireysel arsa büyüklüklerinin dağılımını kullanan indekslere (Simmon's indeks ve Januszewski indeks) göre daha gerçekçi sonuçlar vermektedir. Çünkü arazi parçalılık problemi mekansal bir olgudur. Januszewski ve Simmons's indekslerinin kullanımı her ne kadar daha yaygın olsa da bu indeksler

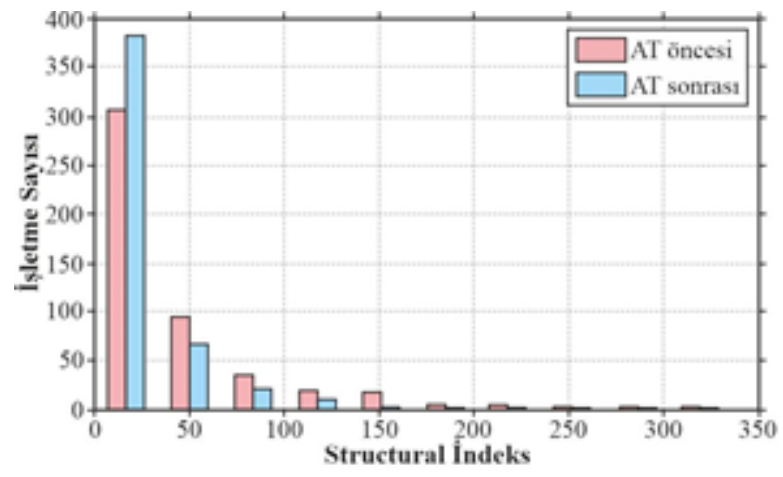

sadece alansal büyüklüğü değerlendirdiğinden tam olarak doğru bir sonuç vermemektedir. Average distance of a hectare indeksi, Grouping indeks, Structural indeks, Scattering indeks değerleri bu anlamda bu eksikliği kapatarak hem alansal büyüklüğü hem de parseller arasındaki mesafe faktörünü kullanarak arazi parçalılığını ölçen indekslerdir ve AT projelerinin değerlendirilmesinde bu indekslerin kullanılması önerilmektedir.

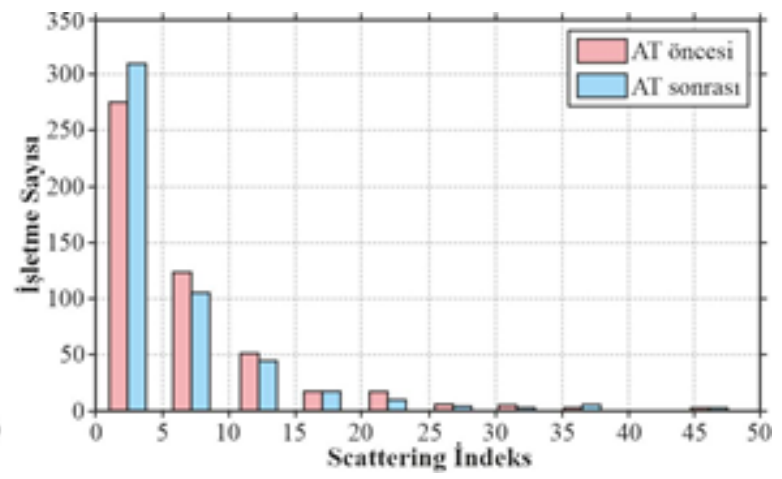

Şekil 9. Wysoka için AT öncesi ve sonrası Structural Indeks ve Scattering İndeks değerleri

Çıkar Çatışması Beyanı: Makale yazarları aralarında herhangi bir çıkar çatışması olmadı̆̆ını beyan ederler.

Araştırmacıların Katkı Oranı Beyan Özeti: Yazarlar makaleye eşit oranda katkı sağlamış olduklarını beyan ederler.

\section{Kaynaklar}

Akkaya Aslan, Ş. 2018. Arazi Toplulaştırma öncesi ve sonrası arazi parçalılık değişimlerinin analizi: Denizli Tavas ilçesi Pınarlar köyü örneği. TÜRK Tarım ve Doğa Bilimleri Dergisi, 5 (3), 364-371.

Ayten B. 2019. Arazi Toplulaştırma projelerinde uygulanan derecelendirme çalışmalarında yeni bir yaklaşım önerisi: Konya-ÇandırKırsal mahallesi örneği. Yüksek Lisans Tezi, Aksaray Üniversitesi Fen Bilimleri Enstitüsü, $85 \mathrm{~s}$.

Ciaian, P., Guri, F., Rajcaniova, M., Drabik, D., Gomez, Y., Palomaa, S. 2018. Land fragmentation and production diversification: A case study from rural Albania. Land Use Policy, 76, 589-599.

Deininger, K., Monchuk, D., Singh, S. K., Nagarajan, H. K. 2014. Does land fragmentation increase the cost of cultivation? Evidence from India. The World Bank Policy Research Working Paper, 7085, http://dx.doi.org/10.1080/00220388. 2016. 1166210.

Demetriou, D., Stillwell, J., See, L. 2013. A new methodology for measuring land fragmentation. Computers, Environment and Urban Systems, 39, 71-80.

Ekinci, K., Sayılı, M. 2010. Tarım arazilerinin parçalanmasını önlemeye yönelik mevzuat üzerine bir inceleme. Gaziosmanpaşa Üniversitesi Ziraat Fakültesi Dergisi, 27 (2), 121-129.

Ertunç, E. 2020. Analysis of the effect of land consolidation projects in terms of land fragmentation and parcel shapes: the case of Konya, Turkey. Arabian Journal of Geosciences, $13 \quad$ (10), https://doi.org/10.1007/s12517-020-053444.

Gonzalez, X. P., Marey, M. F., Alvarez, C. J. 2007. Evaluation of productive rural land patterns with joint regard to the size, shape and dispersion of plots. Agricultural Systems, 97, 52-62.

Hartvigsen, M. 2014. Land reform and land fragmentation in Central and Eastern Europe. Land Use Policy, 36, 330-341, https://doi.org/10.1016/j.landusepol.2013. 08.016.

Hristov, J. 2009. Assessment of the impact of high fragmented land upon the productivity and profitability of the farms. The Case of the Macedonian Vegetable Growers, s. 23, http://stud.epsilon.slu.se/472/1/Hristov_J_ 010909.pdf.

Janus, J., Markuszewska, I. 2017. Land consolidation - A great need to improve effectiveness. A case study from Poland. Land Use Policy, 65, 143-153. 
Januszewski, J. 1968. Index of land consolidation as a criterion of the degree of concentration. Geographia Polonica, 14, 291-296.

Jürgenson, E. 2016. Land reform, land fragmentation and perspectives for futurelandscape consolidation in Estonia. Land Use Policy, 57, 34-43.

Katona, J., Czimber, K., Pődör, A. 2017. Land consolidation based on cluster analysis. Acta Polytechnica Hungarica, 14 (4), 141-154.

Latruffe, L., Piet, L. 2014. Does land fragmentation affect farm performance? A casestudy from Brittany, France. Agricultural Systems., 129, 68-80, 10.1016/j.agsy.2014.05.005.

Looga, J., Jüngerson, E., Sikk, K., Matveev, E., Maasikamäe, S. 2018. Land fragmentation and other determinants of agricultural farm productivity: The case of Estonia. Land Use Policy, 79, 285-292.

Manjunatha, A., Anik, A. R., Speelman, S., Nuppenau, E. 2013. Impact of land fragmentation, farm size, land ownership and crop diversity on profit and efficiency of irrigated farms in India. Land Use Policy, 31, 397-405.

Markuszewska, I. 2013. Land consolidation as an instrument of shaping the agrarian structure in Poland: A case study of the Wielkopolskie and Dolnoslaskie Voivodships. Quaestiones Geographicae, 32 (3), s. 56.

Popov, A. 2017. Assessment of land fragmentation based on the information obtained from four village councils in Poltava and Kharkiv regions. Economic Annals-XXI, 164 (3-4), 5660.

Simmons, A. J. 1964. An index of farm structure, with a Nottinghamshire example. East Midlands Geographer, 3, 255-261.

Vijulie, I., Matei, E., Manea, G., Cocos, O., Cuculici, R. 2012. Assessment of agricultural land fragmentation in Romania, a case study: Izvoarele commune, Olt County. Acta Geographica Slovenica, 52 (2), 403-430. 